\title{
SUPPORTING MANAGEMENT OF EUROPEAN REFUGEE STREAMS BY EARTH OBSERVATION AND GEOINFORMATION
}

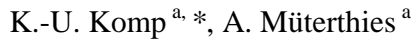 \\ ${ }^{\text {a }}$ EFTAS - Remote Sensing Transfer of Technology. Muenster, Germany - \\ klaus.komp@eftas.com, andreas.mueterthies@eftas.com
}

SpS 16 - EARSeL

KEY WORDS: Refugee streams, Data Mining, Earth Observation, Detecting habitation reserves

\begin{abstract}
:
The sharp increase in refugee numbers arriving in the European Union has recently caused major and manifold challenges for the member states and their administrative services. Location based situation reports and maps may support the refugee management from local to European level. The first support is mapping of the geographical distribution of migrating people which needs more or less real time data. The actual data sources are location related observations along the routes of refugees, actual satellite observations and data mining results. These tools and data are used to monitor spatial distributions as well as extrapolate the arrival of refugees for the subsequent weeks. The second support is the short term update of the location of initial registration facilities and first reception facilities, their capacities, and their occupancy. The third management level is the systematic inquiry for unoccupied housing facilities and for empty places within build-up areas. Geo-coded data sets of house numbers have to be cross-referenced with city maps and communal inhabitants address data. The legal aspects of data mining and secured access to personal data are strictly controlled by the administration allowing only limited access and distribution of data and results. However, the paper will not disclose scientific progress in Earth Observation and GIS, but will actually demonstrate an urgently needed new combination of existing methods to support actual needs. The societal benefits of EO/GIS are no longer just potential possibilities, but actual results in real political, administrative and humanitarian day to day reality.
\end{abstract}

\section{INTRODUCTION}

The sharp increase in refugee numbers arriving in the European Union has recently caused major and manifold challenges for the member states and their security forces and administrative services. The actual situation of refugees in Europe will require long term collaboration of different member states and in Germany the collaboration at all administrative levels and territorial units. Location based situation reports and maps may support the refugee management from local to European level.

Persons arriving at the outer borders of the European Union have mostly endured enormous stress and pain during their migration and have dared to leave their home environment because of severe circumstances of famine, natural hazards, political pressure, ethnical or religious conflicts, warlike operations, destruction of infrastructure and housing and various aspects of living in misery. Before making premature judgements on the quality of those reasons for migration, we should remember that during the last 250 years the reasons for emigrating from Europe, immigrating to Europe and the migrations within Europe due to different wars were comparable to current reasons.

\section{ACTUAL CHALLENGES IN EUROPE}

\subsection{Monitoring Migrating People}

The first level of support is the supply of information on the geographical distribution of migrating people which needs more or less real time data to deal with the exceptional circumstances in Central Europe. Therefore a bundle of methods and techniques summarized as GeoIT $^{1}$ needs to be applied under special legal frame conditions for access to administrative data and their incorporation into spatial processing. Within the European Union there is a legal basis for the administrative data exchange established through the INSPIRE directive under which not only the administrative framework but also the harmonization of data exchange formats were developed.

2.1.1 The International Relief Programme DRP: Esri Germany has developed an international relief program: the Esri Disaster Response Program (DRP). This is a complete GeoIT software which will be granted free of charge to build up an integral information platform reserved to administrative application. The actual data sources are location related observations from police forces of different member states along the routes of refugees between the Mediterranean shores and the Northern member states of the EU, from NGOs, private

\footnotetext{
GeoIT comprises the totality of hardware, software, techniques and/or methods for the acquisition, analysis and presentation of geographical data and spatial information in diversified technological pillars like remote sensing, satellite navigation or Geo Data Infrastructures.
}

\footnotetext{
* Corresponding author
} 
observations by cellular phones, actual satellite and aerial images and further information from data mining activities. These tools and data are already used to monitor the southern spatial distributions of refugees as well as extrapolate impending arrivals in subsequent weeks.

The International Organization for Migration (IOM) was born in 1951 out of the chaos and displacement of people across Western Europe following the Second World War under the name of the "Provisional Intergovernmental Committee for the Movement of Migrants from Europe". Today it has the status of a worldwide operating agency with 162 member states and an annual budget of 1.3 billion USD (IOM 2016). Among others IOM provides different surveys on migration updated nearly weekly, like the example of stranded migrants and refugees between Turkey and South-eastern Europe (see fig. 1).

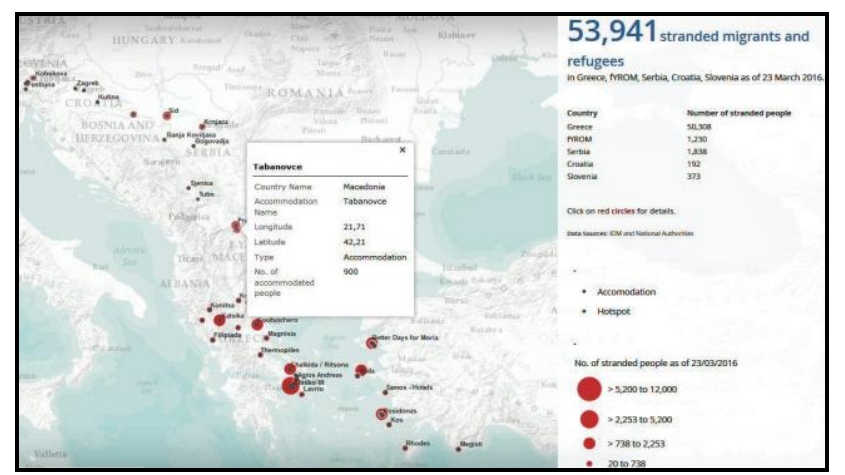

Figure 1: Interactive map monitoring of stranded migrants as of 23 March 2016 published by IOM platform for monitoring and analysis (IOM 2016).

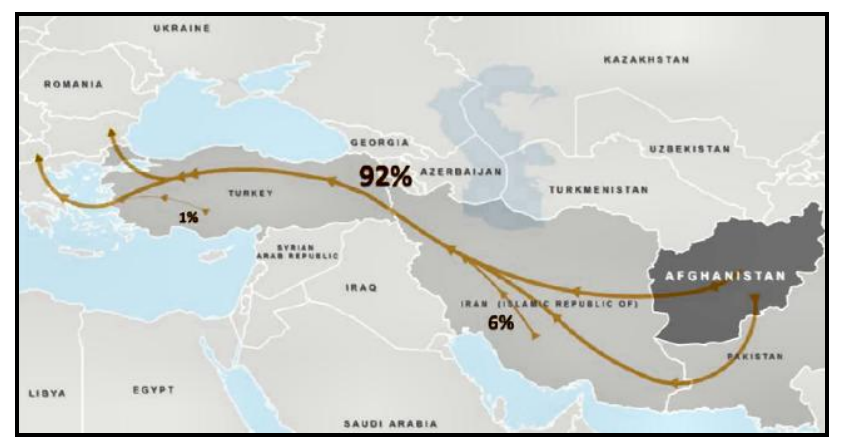

Figure 2: Survey of migrant flow monitoring - results for Afghanistan migrants (IOM 2016).

Another example is taken from IOM survey activities with migrant questionnaires about routes, organization and prices paid for the transfers to the date of 14 March 2016 (see example Afghanistan in fig. 2).

Furthermore within the member states concerned, the administrations have already installed online platforms for existing infrastructure for arriving refugees, like interactive maps of initial reception facilities and local immigration offices. While in Germany the central services are organised by the BAMF - Federal Office for Migration and Refugees and the GeoIT services by the BKG - Federal Agency for Cartography and Geodesy (BKG 2016), there are various local initiatives developing migrant oriented city maps for mobile devices.
2.1.2 Migration Potentials in the Regions of Origin: The ad hoc reaction on streams of migrating persons between Turkey, the Maghreb states and Europe is only one side of the problem, a closer view on the regions of origin will become more important in the forthcoming years. The knowledge of actual trends in settlement sprawl and urbanisation, rural land use and agricultural production in relation to population dynamics, employment, health and educational infrastructure needs to be intensified urgently and updated regularly. The role of Earth Observation in combination with geo-statistic methods and GIS techniques has been pointed out intensively with the focus on improvement of the living conditions in Africa (Komp et al. 2010).

Looking beyond the actual refugees coming from the civil war regions of Syria, there is a constant growing migration potential in sub-Saharan Africa for various reasons. The widespread financial aid from Saudi Arabia throughout the last 30 years, building mosques and Islamic schools in tropical Africa, could be seen as one driving factor for the growing number of war lords and Islamic terror groups besides tribal conflicts. Dangerous living conditions following the burning down of villages, kidnapping and tortures have often hindered the agricultural work and the cattle transhumance. These were the widespread reasons why agricultural areas could not be tilled in due time, this being an additional factor for yield reduction besides agro climatologic failures. In response to the 1984-85 famines in Sudan and Ethiopia, the US Agency for International Development (USAID) created the Famine Early Warning System. Today the network FEWS NET publishes worldwide geospatial analyses to anticipate impending famines and advise policy makers on how to prevent or mitigate such famines. More than 20 institutions collaborate to analyse different satellite data, agro-climatology reports, environmental and food market issues, rainfall estimates and atmospheric monitoring of weather patterns such as El Nino and La Nina events. Besides several American agencies, partners also include the Comité permanent Inter-Etats de Lutte contre la Sécheresse dans le Sahel in West Africa and the Food Security and Nutrition Analysis Unit in Somalia.

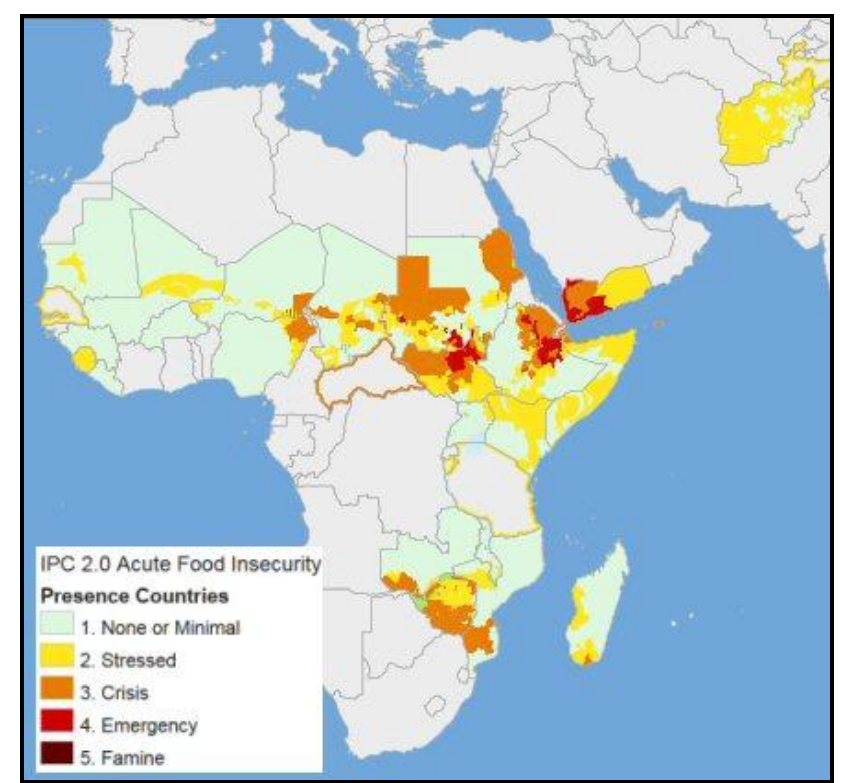

Figure 3: Acute Food Insecurity predicted in March 2016 for period June - September 2016 in Africa and Middle East

(FEWS Net 2016). 
One of the service products of FEWS Net is the analysis of the actual food insecurity in countries under observation in Central America, tropical Africa and Middle East. Besides the actual evaluation, FEWS also creates a prediction for the forthcoming period, like the publication in March 2016 of food insecurity for the period June to September 2016 displayed in Figure 3 (FEWS Net 2016). The regions classified as "emergency" or "crisis" are concentrated around the Lake Chad, the western and eastern parts of Sudan, South Sudan, the northern part of Ethiopia, Djibouti and the western part of Yemen. With respect to the political and economic situation in those countries there will be no major change without aid from outside, which means that there is an increasing probability that parts of the population concerned will try to emigrate.

Another approach to the problem had already been launched by the European Space Agency (ESA) in 2003 as a contribution to the joint EU/ESA programme Global Monitoring for Environment and Security (GMES), recently renamed COPERNICUS. It is called Global Monitoring for Food Security (GMFS) and was an ESA Earth Watch GMES Service Element, initially designed for nine African countries and coordinated by VITO from Belgium. With a focus on remote sensing, the methods and results have already been reported to the Commission VIII, WG VIII/6 in Melbourne by Komp and Haub (Komp \& Haub 2012). Furthermore the combination of evaluated SAR data, classified SPOT data and stratified agrostatistical ground sampling has been developed and implemented by EFTAS in its role as GMFS coordinator for East Africa (Haub et al. 2013) and handed over to the Sudanese Government as a result of the technology transfer to the responsible user, the Federal Ministry of Agriculture and Irrigation.

\subsection{Locational Inventory of Facilities and Capacities}

The second level of support comprises the short term update of the location of initial registration and initial reception facilities, their capacities, and their occupancy classified according to

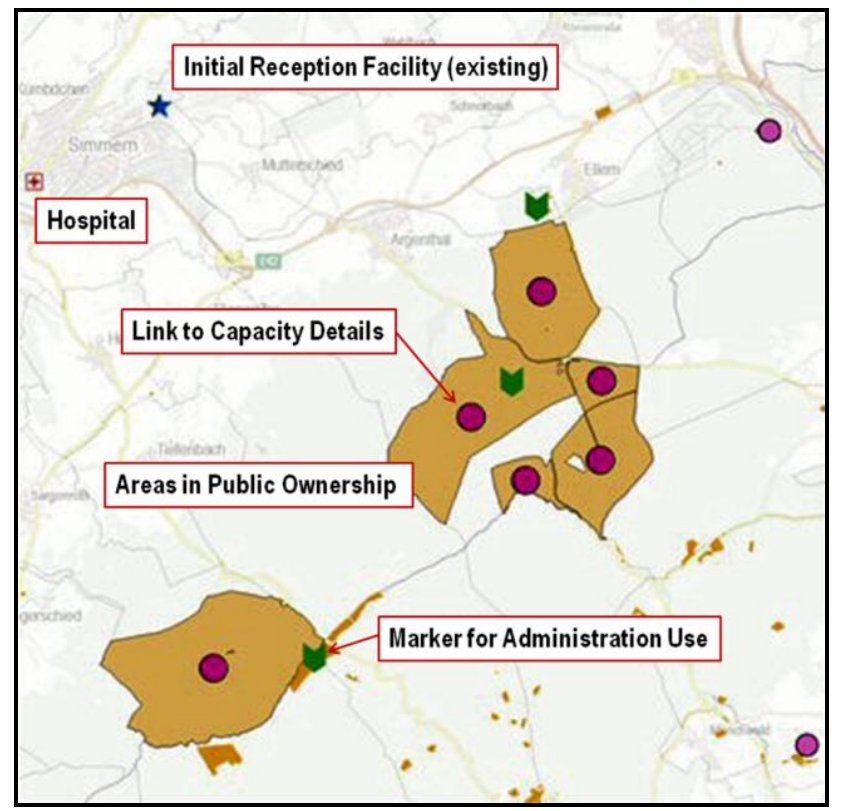

Figure 4: Administrative Web Portal for infrastructure and potential areas for refugees in public ownership (Bernkastel-Wittlich 2016). ethnical or national criteria. In the case of Germany, there is a Federal Coordination Office (KoSt FV Bund) which is mandated to support the management and distribution of refugee streams by coordination on the federal level. This office is supported by the Federal Office of Civil Protection and Disaster Assistance (BBK) through graphical transfer of listed data into geo-spatial views on the actual situation of refugee arrivals. Additionally, the Center for Satellite Based Crisis Information (ZKI), located at the German Aerospace Center (DLR), provides actual satellite data from the relevant border checkpoints.

The federal state Rheinland-Pfalz for instance has established within its central data processing center a GeoIT infrastructure for the management of refugees in the shortest delay, based on the participation in the DRP program. The actual demand for spatial information is concentrated on the design and operation of initial reception centers, their capacity and occupancy, identification of public immovables and the update of that information. With respect to copyright and privacy restrictions, figure 4 does not show up-to-date details but has been selected to give a good impression of the working results.

Presently, those solutions are under operational application in the Ministry of Interior Affaires and subordinated services. Further derived applications will be made available through personalized accounts to interested user groups. The services of the state central data processing center will be made accessible through a cloud service by Esri Germany.

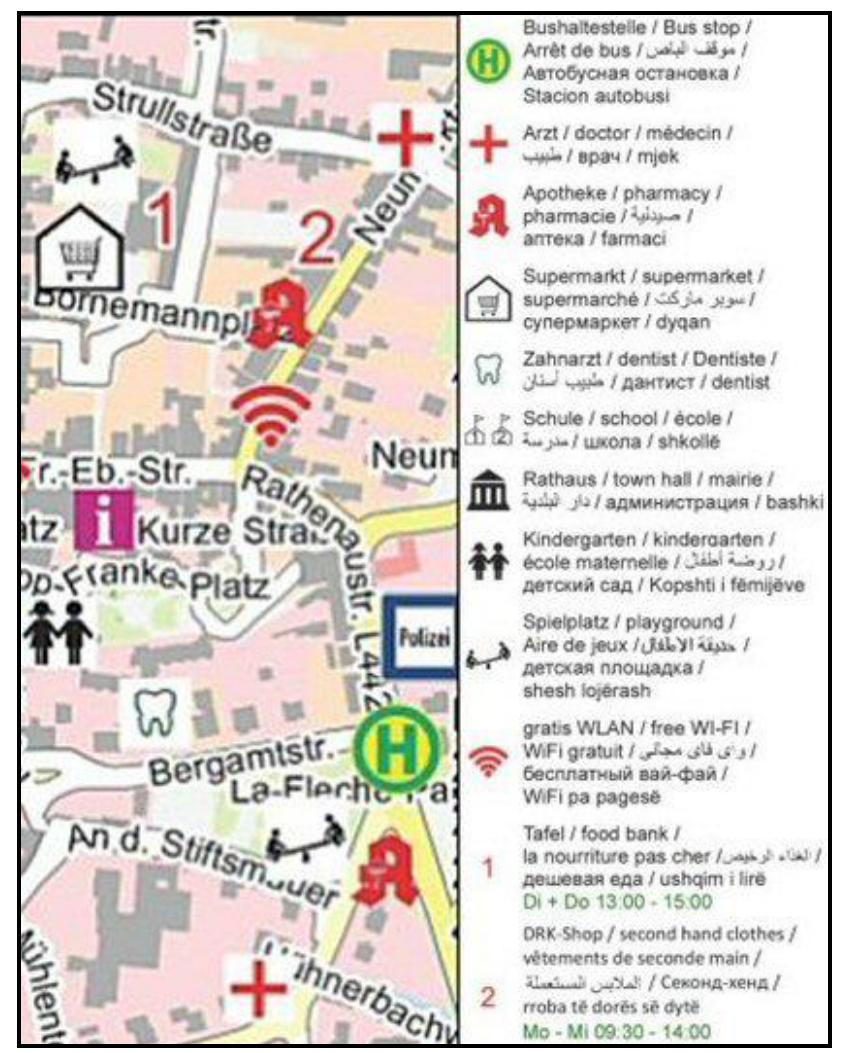

Figure 5: Special City Map for Refugees of the City of Obernkirchen with a legend in six languages (Stübke 2015).

Another geo-spatial application is going to be distributed on communal level, but in relation to central design. In the federal 
state of Niedersachsen the publication of special city maps for refugees is promoted based on the model of the city of Obernkirchen. The regional directorates within the State Office of Geoinformation and Surveying Niedersachsen (LGLN) support interested cities that plan to prepare annotated city maps considering the basic needs of refugees (following the example displayed in figure 5). Indications and map signatures for doctors, pharmacies, bus stops, schools or second hand clothing are mapped and explained in a multilingual legend in German, English, French, Arabic, Russian and Albanian.

\section{SUPPORTING MID-TERM INTEGRATION STRATEGIES}

\subsection{Housing and Educational Infrastructure as Main Factors towards Integration}

As those initial reception facilities should have only transitional character, people have to be offered specific and affordable housing facilities which will allow integration, education, vocational training and employment. Because in Europe fewer employees will be needed in the agricultural sector, immigrants will have to apply for work in towns and cities and will also seek urban housing space. The environmental development targets to limit additional land consumption require nota bene urban densification. This can be done primarily by filling up existing vacancies and secondly by activating gap sites within the urban perimeters.

Furthermore, the fact that a considerable part of refugees could not benefit from school education during war and migration, they not only have to learn a new language, but in many cases also catch up basic alphabetization. All infrastructures necessary for obtaining language command, school-leaving qualification and professional qualification in the European frame will only be available in towns or cities. Therefore, European cities will have to deal with a remarkable increase in population, which will again require increasing capacities of crèches, day care centers, schools and vocational training centers.

\subsection{Geospatial Detection of Housing Vacancies}

The third level of management which is going to be implemented is the systematic inquiry for unoccupied housing facilities and for empty places within build-up areas. Geo-coded data sets of house numbers in streets have to be crossreferenced with large scale city maps and the communal inhabitant's address data. Legal soil occupation plans, additional satellite or aerial images plus communal horizontal street views allow a first categorization of suspected vacancies in potentially eligible houses.

Basically, those postal house addresses with no person registered to, are suspected to be vacant. And if such a vacancy will not unmask an illegal occupancy or turn out to be a temporal vacancy, there are administrative possibilities to motivate the owner to rent the vacant space. Another approach can be the utilisation of underused commercial buildings, which could be rented temporarily for living. In Germany and under the umbrella of the State Office of Geoinformation and Surveying Niedersachsen (LGLN), the federal state of Niedersachsen has developed software packages which allow the described evaluations while the use of personal data from the inhabitants register is controlled through administration.

With regard to the public presentation, the map basis of figure 6 has been cleared from street names and similar identifiers. The results show in red colours those plots with vacancies in parcels dedicated to be used for living. The blue colour shows "underused" parcels with commercial assignment, where subsequent local inspections have to clarify the residential possibilities.

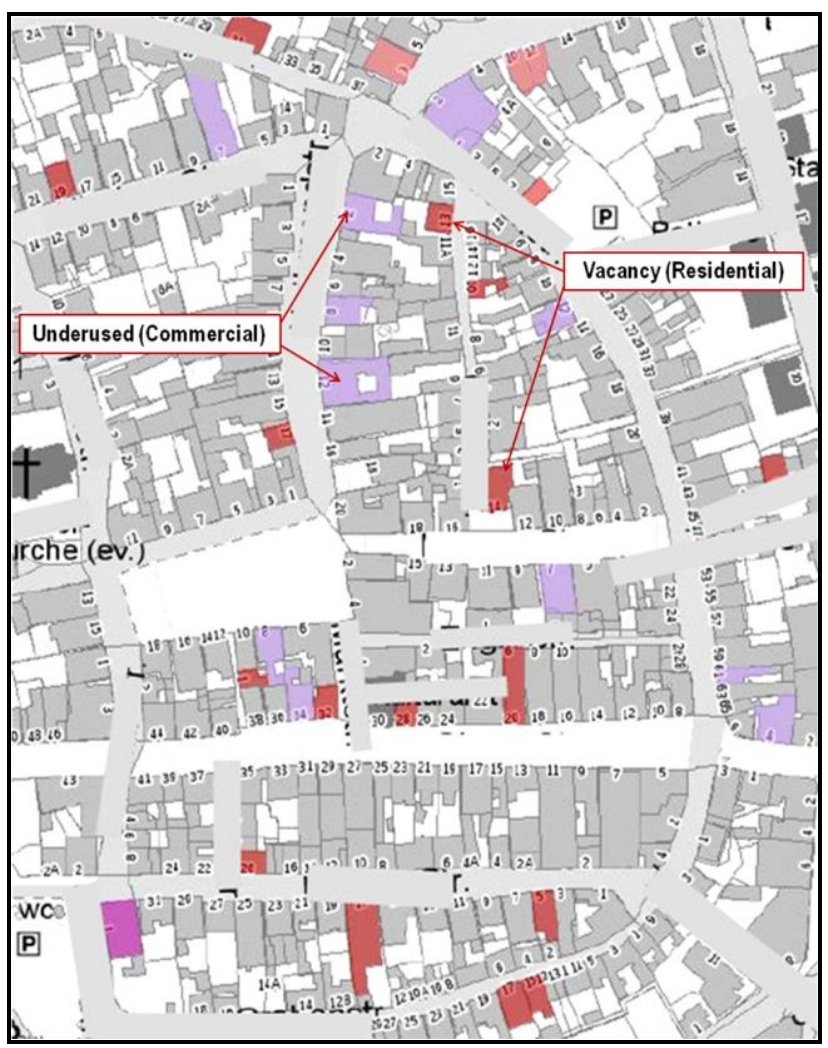

Figure 6: Example of an inventory on vacancy (LGLN 2016).

The basic statistic data of the registered inhabitants contains among other data also the birth date, which has allowed the working group of Doris Kleinwächter within the LGLN to calculate the youngest inhabitants per address. This data can then be displayed not only in specific maps, but also allows computing the number of inhabitants within a certain perimeter that will enter primary school in three years time.

\subsection{Geospatial Detection of Construction Potentials}

The following example has been taken from the same administrative working group. Within build-up areas there are a certain number of parcels which have not been used for construction for different reasons. In the first decades after World War II those parcels often consisted of bombed buildings which were not reconstructed because of unclear heritage or ownership or just lack of funds. Whereas in city centers such gap sites have disappeared by infill, in towns and outskirts of cities such building reserves still exist. These reserves usually have all the technical infrastructure like water supply, connection to sewage system, electricity and street access. Therefore, the personal and public investment for new construction will always be lower than opening any new perimeter for construction. 
The evaluation starts with overlaying urban or cadastral basic map data with building layer and limits of the legal boundaries for build-up area. The parcels without any building recorded will be highlighted and differentiated according to possible use for housing, commercial or other. Subsequently, the highlighted parcels will be inspected in Orthophoto or VHR satellite data to find out whether there are other obstacles like a ditch or power line to be taken into account. Figure 7 shows such a case in a suburban environment where the communal administration may negotiate with the owner(s) the potential for housing investment at that place.

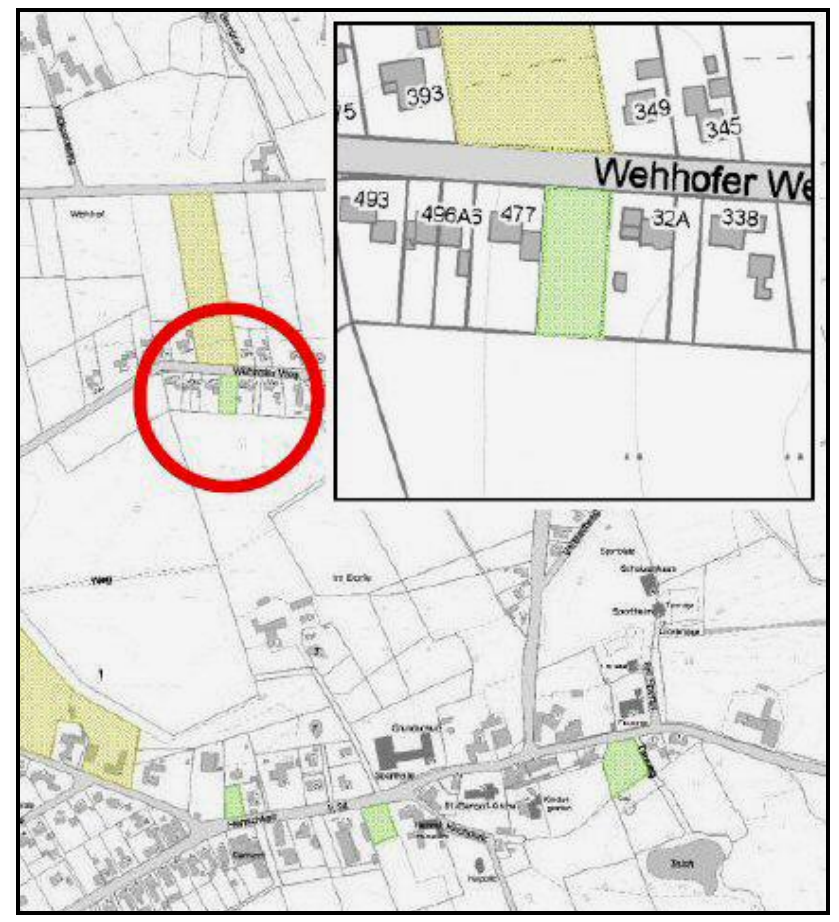

Figure 7: Inventory of potential construction sites (Kleinwächter 2014).

This example also shows how EO methods plus data mining from urban data allow a first detection of vacant lots and their potential for additional housing construction. Normally the discovery of such potential densification potential will lead to amicably negotiations without having to take legal action in the interest of the general public.

\section{SOCIETAL BENEFITS OF EO \& DATA MINING}

\subsection{Societal Benefit Areas of Earth Observation}

Upcoming trends include not only more continuity of data with higher resolution, the harmonization and standardization of mapping procedures, but also emerging user demands and new user communities related to web services. Finally, these prospects will broaden the user community who sees the Societal Benefit Areas (SBA) of Earth Observation. This will be the common mandate for all researchers and experts involved to support the advancement of Earth Observation (cf. Mora 2014). Their engagement in Earth Observation and high-resolution land cover monitoring will contribute to a responsible and sustainable development of our planet Earth.

\subsection{Data Mining for the Potentials of Refugee Integration and Legal Aspects}

The acquisition, processing, storage and dissemination of person related data have become an important issue in the European Union affecting not only the social and commercial handling of data but also the administrative procedures. The subjective value of the protection of private data is sometimes considered in the published opinion to dominate even legal and security demands of democratic states. The general provisions and rules for processing personal data have been adopted through the Directive 95/46/EC of the European Parliament and of the Council of 24 October 1995 on the protection of individuals with regard to the processing of personal data and on the free movement of such data. Certain procedures and techniques of data mining with respect to the management of refugee demands thus require the application of Article 13 (a), (c), (d) of this Directive to adopt measures by the Member States (European Commission 1995).

To safeguard national security, public security etc., the Republic of Germany has passed the Data Exchange Improvement Law on 14 January 2016 (Bundesrepublik Deutschland 2016), which allows and requires registration of each migrating person in a way that multiple identities will be excluded in future. Both legal provisions constitute the administrative basis for the application of the geo-data evaluations described above (Bernsdorf et al. 2015).

Great parts of Central Europe can rely on accurate geo-data, housing and infrastructural information and citizen registers, which will more or less allow the widespread application of the described system of a powerful GeoIT which should not be restricted to the border of member states. However, in those member states that lack cadastral data, maps and geo-coded household data, other non-governmental sources have to be used, such as car navigation data, web based map data, address data of post and parcel services or VHR satellite data, in short, data that can be geo-coded to allow similar evaluations. The latter are urgently needed by the concerned administrations dealing with the management of refugees.

Even if the actual wave of refugees will calm down, the observation of food insecurity combined with economic weakness in Sub-Saharan Africa is clearly indicating the next waves of migrants towards Europe. The lack of data due to the termination of systematic mapping by French and British services following independencies throughout the 50ies and 60ies of the last century could not be caught up. In these areas, the primary source of information will be up-to-date satellite data of different type to monitor agro-climatology, land use change and urbanisation. Fortunately, the Landsat continuation policy and the European series of SENTINEL satellites will provide an affordable stream of actual data, which could be used to observe and to mitigate the situation in the countries concerned.

\section{CONCLUSIONS}

The increased number of migrating persons arriving in Central Europe during the last two years has initially created overwhelming sympathy and compassion, but has created an unexpected additional burden for public security and administrations. Even if sympathy and compassion have cooled 
down due to a decreasing migratory flow we could see that the professional integration of elements of GeoIT results into the work of security forces and voluntary citizen groups, helped to establish working routines to channel the first reception of migrants.

Based on these experiences, it became obvious that those migrants cannot stay long-term in initial reception facilities and that the real mid- and long-term work of integration will continue for the next ten years at least. Subsequent to the learning of the language as the basic competence, the challenge will be to organise housing, alphabetization, education, vocational training and employment for these migrants. Several examples outlined in this paper could demonstrate the benefit of GeoIT application for the German administration as well voluntary groups to handle the flow of refugees.

Finally, it should not be neglected that many of the connected issues and challenges are not basically new, but have reached a quantitative new dimension and will be exposed to new application areas now and even more in future.

In the case of Earth Observation/GIS support to the management of refugee streams, it becomes obvious that the societal benefits of EO/GIS are no longer just potential possibilities, but actual results in real political, administrative and humanitarian day to day reality.

\section{ACKNOWLEDGEMENTS}

The authors would like to thank the German Umbrella Association of Geo Information (DDGI) and its task force "Refugee Management" for their support and access to working material.

\section{REFERENCES}

Bernkastel-Wittlich, 2016: Flüchtlingshilfe - Angebote vor Ort. Web portal of regional administration. http://kv-bkw.maps. arcgis.com/apps/webappviewer/index.html?id=e55251d29d0c4 bf7b84d440569f97623 (02-04-2016)

Bernsdorf, B., Bierbrauer, H., Büscher, O., Müterthies, A., Pakzad, K., Wenzel, Th. \& Woditsch, S. 2015: Data-Mining Gesellschaftspolitische und rechtliche Herausforderungen Data-Mining mit Geodaten. - 257 pp. - Expert Opinion established on behalf of TAB (Office of Technology Assessment at the German Bundestag), EFTAS Remote Sensing Transfer of Technology, Münster.

BKG 2016: TopPlus-Web-Refugees. Interactive map service free of charge in the frame of refugee relief actions until 31.12.2017. Frankfurt. http://www.geodatenzentrum.de/ geodaten/gdz_rahmen.gdz_div?gdz_spr=deu\&gdz_user_id=0\& gdz_akt_zeile=4\&gdz_anz_zeile=5 (01-04-2016).

Bundesrepublik Deutschland 2016: Datenaustauschverbesserungsgesetz: Gesetz zur Verbesserung der Registrierung und des Datenaustausches zu aufenthalts- und asylrechtlichen Zwecken. Berlin 02 Februar 2016. Bundesgesetzblatt Teil 1. 2016 - 5. Bonn, pp. 130-155.
European Commission 1995: Richtlinie 95/46/EG vom 24. Oktober 1995. Richtlinie zum Schutz natürlicher Personen bei der Verarbeitung personenbezogener Daten zum freien Datenverkehr. Amtsblatt der Europäischen Gemeinschaften L-281 vom 23.11.1995, pp. 31-50.

FEWS Net, 2016: Famine Early Warning Systems Network. IPC 2.0 - Acute Food Insecurity Phase. http://www.fews.net/; (31-03-2016).

Haub, C., Kleinewillinghöfer, L., Brockmann, J., Komp, K. \& Gilliams, S., 2013: Monitoring Services for Food Security Successful Transfer of Technology to the Sudanese Government. - PFG - Photogrammetrie, Fernerkundung, Geoinformation 2013 (5): pp. 459-472.

IOM 2016: Analysis: Flow Monitoring Surveys in the Mediterranean and Beyond. http://doe.iom.int/docs/Analysis $\% 20-\% 20$ Flow\%20Monitoring\%20Surveys $\% 20$ in $\% 20$ the $\% 20$ Mediterranean\%20and\%20Beyond\%20-\%2017\%20Mar\%2020 16.pdf; (30-03-2016).

Komp, K., Dienst, H. \& Haub, C., 2010: Anwendungspotenziale der Erdfernerkundung für Entwicklungsländer. Erkenntnisse aus dem Technologietransfer - politische und gesellschaftliche Bedingungen für den Einsatz der Fernerkundung in Entwicklungsländern. - 57 pp., Expert Opinion established on behalf of TAB (Office of Technology Assessment at the German Bundestag), Münster, published within: TAB 2012. Fernerkundung - Anwendungspotenziale in Afrika, AB 154. Berlin.

Komp, K. \& Haub, C., 2012: Global Monitoring for Food Security and Sustainable Land Management - Recent Advances of Remote Sensing Applications to African and Siberian Show Cases. - International Archives of Photogrammetry, Remote Sensing and Spatial Information Sciences XXXIX-B8, 2012: pp. 265-270, Melbourne, Australia.

Kleinwächter, D., 2014: Baulücken- und Leerstandskataster für niedersächsische Kommunen. PR Communication of LGLN. Hannover, 42 pp.

LGLN 2016. Baulücken- und Leerstandskataster Niedersachsen http://www.gll.niedersachsen.de/portal/live.php?navigation_id= 10605\&article_id=111411\&_psmand=34; (31-03-2016).

Mora, B., Tsendbazar, N.-E., Herold, M. \& Arino, O., 2014: Global land cover mapping: current status and future trends. Land use and land over mapping in Europe: practices \& trends. - Remote Sensing and Digital Image Processing 18: pp. 11-30, Dordrecht, the Netherlands.

Stübke, Th. et al., 2015: Stadtplan Oberkirchen für Flüchtlinge. Bearbeitet im Katasteramt Rinteln, Hg. LGLN Hannover. 